\title{
Erratum to: Gender differences in apoptotic signaling in heart failure due to volume overload
}

Melissa R. Dent $\cdot$ Paramjit S. Tappia Naranjan S. Dhalla

Published online: 8 May 2011

(C) Springer Science+Business Media, LLC 2011

Erratum to: Apoptosis (2010) 15:499-510

DOI 10.1007/s10495-009-0441-8

The original published article contained two errors in Fig. 2. While preparing Fig. 2A and Fig. 2D, the representative blots for GAPDH and caspase 3 were shown incorrectly. This mistake has now been corrected and the new Fig. 2 along with its legend is displayed as follows.

The online version of the original article can be found under doi:10.1007/s10495-009-0441-8.

M. R. Dent · P. S. Tappia · N. S. Dhalla $(\square)$

Department of Physiology, Faculty of Medicine, Institute of Cardiovascular Sciences, St. Boniface General Hospital Research Centre, 351 Tache Avenue, Winnipeg,

MB R2H 2A6, Canada

e-mail: nsdhalla@sbrc.ca

\section{P. S. Tappia}

Department of Human Nutritional Sciences, Faculty of Human

Ecology, University of Manitoba, Winnipeg, MB, Canada 
Fig. 2 mRNA levels for caspases 3 and 9 in male and female rats at 4 weeks and 16 weeks post-AV shunt.

Representative blots of caspases 3 and 9 at 4 weeks (a)

Quantified data of caspase 3 (300 bp) (b) and caspase 9 (510 bp) (c) at 4 weeks.

Representative blots of caspases 3 and 9 at 16 weeks (d).

Quantified data of caspase 3

(e) and caspase 9 (f) at 16 weeks. Values are mean $\pm \mathrm{SE}$ of three experiments. Ratios of target gene to GAPDH are expressed as \% of control values. $* P<0.05$ versus corresponding sham control values; ${ }^{\#} P<0.05$ versus corresponding value for other gender

A Blots: 4 wks
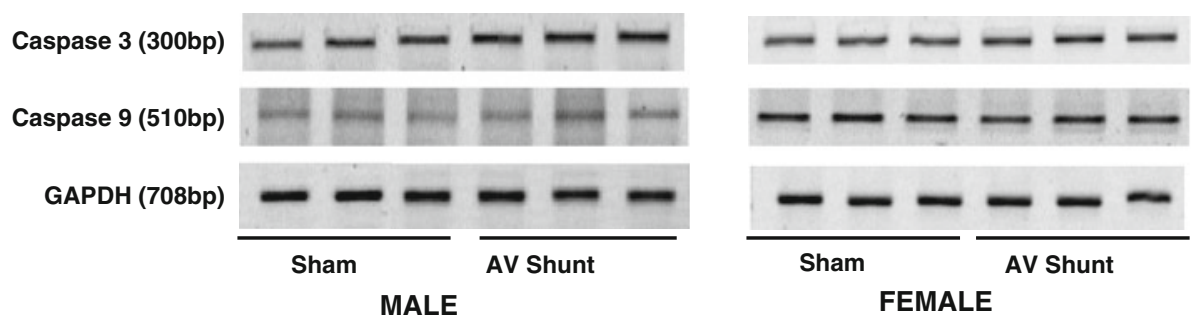

B Caspase 3 mRNA
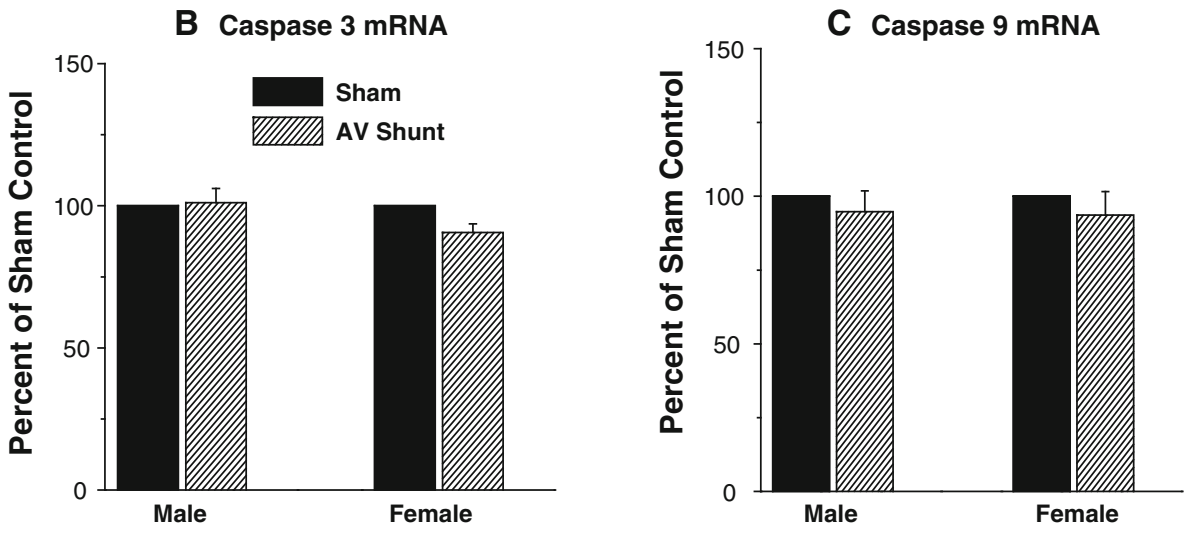

D Blots: 16 wks
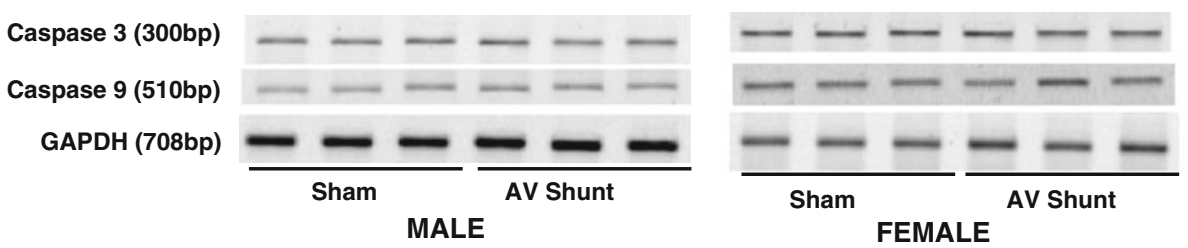

E Caspase 3 mRNA

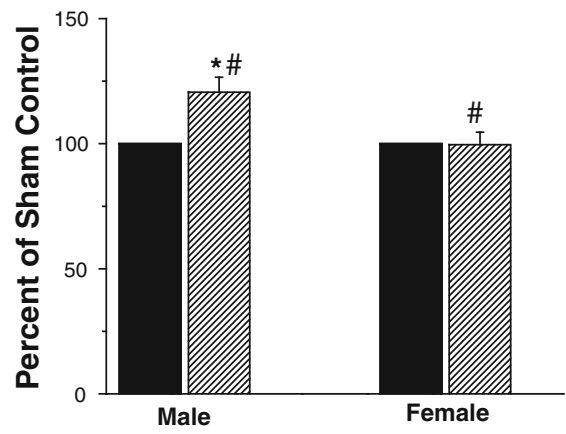

F Caspase 9 mRNA

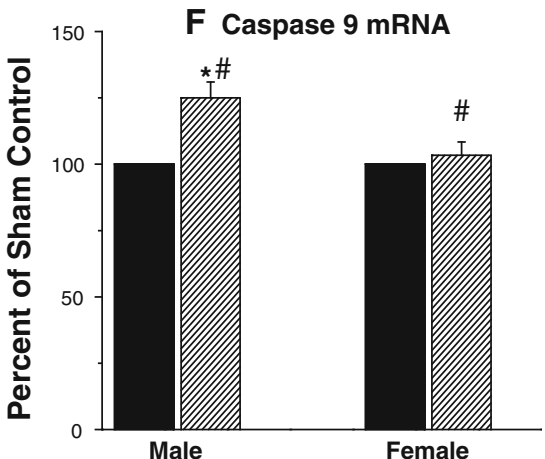

